\title{
An Experimental Study on the Simultaneous Effect of Nanofluid and Tube Insert on the Thermal Performance of an Automobile Cooling System
}

\author{
A. Karimdoost Yasuri $^{1 \dagger}$ and E. Soleimani ${ }^{2}$ \\ ${ }^{I}$ Department of Mechanical Engineering, Lorestan University, Khuramabad, Iran \\ ${ }^{2}$ Department of Mechanical Engineering, Islamic Azad University, Doroud Branch, Doroud, Iran \\ †Corresponding Author Email: Yasuri.am@lu.ac.ir
}

(Received November 29, 2020; accepted February 19, 2021)

\begin{abstract}
In this research, an experimental study is conducted to investigate the effect of simultaneous use of tube insert and nanofluid on the thermal performance of the automotive cooling system (radiator). $\mathrm{Al}_{2} \mathrm{O}_{3}$-water based nanofluid is used and the flow regime is laminar (Reynolds 1000-1800). For this study, an experimental automotive cooling system is designed and built. Thermal performance of $\mathrm{Al}_{2} \mathrm{O}_{3}$-water nanofluid at three concentrations of $0.1,0.2$ and $0.4 \%$ weight fraction of $\mathrm{Al}_{2} \mathrm{O}_{3}$-water nanofluid compared to water is monitored by variations of flow rate. In this research, a tube insert with a steel wire rod and a sine profile inside the radiator tube is used as a turbulent-maker. The results show that the sole use of nanofluid, without a tube insert inside the radiator, increases the heat transfer coefficient by about $11 \%$, and the use of a tube insert together with distilled water increases heat transfer coefficient by about $35 \%$. Finally, the use of tube insert together with $\mathrm{Al}_{2} \mathrm{O}_{3}$-water based nanofluid at their best mass concentration increases heat transfer coefficient by about $56 \%$.
\end{abstract}

Keywords: Nanofluid; Cooling; Tube Insert; $\mathrm{Al}_{2} \mathrm{O}_{3}$

\section{NOMENCLATURE}

$\begin{array}{ll}\mathrm{A} & \text { area, } \mathrm{m}^{2} \\ \mathrm{C}_{\mathrm{p}} & \text { specific heat, } \mathrm{J} / \mathrm{kg} \mathrm{K} \\ \mathrm{D} & \text { inner diameter of the tube, } \mathrm{m} \\ \mathrm{f} & \text { friction factor } \\ \mathrm{h} & \text { convective heat transfer coefficient, } \mathrm{W} / \mathrm{m}^{2} \mathrm{~K} \\ \mathrm{k} & \text { thermal conductivity, W/m K } \\ \mathrm{L} & \text { length of the tube, } \mathrm{m} \\ \dot{\mathrm{m}} & \text { mass flow rate, } \mathrm{kg} / \mathrm{s} \\ \mathrm{P} & \text { pressure, Pa } \\ \dot{Q} & \text { heat transfer rate }(\mathrm{w}) \\ \mathrm{Re} & \text { Reynolds number } \\ \mathrm{T} & \text { temperature, }{ }^{0} \mathrm{C}\end{array}$

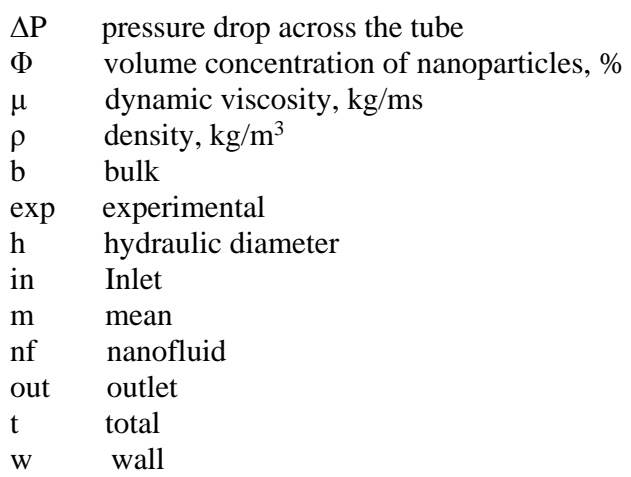

\section{INTRODUCTION}

Nowadays, optimal cooling is one of the necessary needs of industry and inseparable part in desired functioning of much equipment such as computers, electrical equipment and electronics, motor vehicles, high-power lasers, etc. The growing trend in the advancement of various industries, including the aerospace of electronic cars, has been accompanied by an increase in temperatures produced in smaller volumes compared to the past, which shows the growing need for cooling systems in more optimized forms and smaller volumes. As a result of high power consumption of these equipment, more thermal load (in some cases even more than $25 \mathrm{~kW}$ ) and more thermal flux in smaller volumes are produced compared with the past, which has made cooling a major challenge in the industry. However, low thermal properties in conventional fluids is a big obstacle in resolving this basic need effectively. There are now several ways to improve cooling, which can include microchannel heat sink and coolant liquid technology of two-phase flows such as 
heat pipes, thermosyphons, direct immersion cooling, and spray cooling. In the meantime, nanofluid technology shows high potential to improve heat transfer properties with greater efficiency and output, as well as lower costs. Now, using the advances made in modern technology, metal or non-metallic particles with nanoscale dimensions and, therefore, fluids containing these particles can be produced. Nano materials have unique mechanical, optical, electrical, thermal and magnetic properties. Nanofluids are synthesized by suspending nano particles smaller than $100 \mathrm{~nm}$ in base fluids typically such as water, oil, or ethylene glycol. The addition of a very small amount of nanoparticles in base fluid in a uniform and stable manner increases thermal properties of the fluid significantly.

With the development of nanotechnology over the past two decades, the use of nanofluid was first introduced by Choi (1995). The main purpose of using nanoparticles is to achieve maximum thermal properties by the minimum particle size (less than $1 \%$ ) that is uniformly distributed in the fluid. After the introduction of nanoparticles, a lot of studies have been done to increase the thermal properties of fluids, and there are many new ideas that have been used extensively in different sectors, such as the new generation of computer coolers and safe nuclear power plant cooler. Nanofluid can be used in heat exchangers, which can significantly reduce the working fluid flow rate resulting in designing smaller heat exchangers. The rapid growth of papers and studies related to this field indicates the importance and high efficiency of nanofluids in improving the properties of fluid heat transfer (Choi et al. 2008).

For the first time, Sharma et al. (2009) examined the relationship between Nusselt number and friction factor for the turbulent flow using $\mathrm{Al}_{2} \mathrm{O}_{3}$-water nanofluid with $0.1 \%$ volume concentration and the twisted tape tube inserts in a plain tube, simultaneously. They achieved an increase in heat transfer of about $23.96 \%$.

Sundar and Sharma (2010) achieved thermal transfer enhancement of about $30.3 \%$ for $\mathrm{Al}_{2} \mathrm{O}_{3}$-water nanofluid with hollow tube and $43 \%$ for this nanofluid and tube with twisted tape inserts.

In another study by Chandrasekar et al. (2011), in the laminar flow regime, the wire coil tube inserts and $\mathrm{Al}_{2} \mathrm{O}_{3}$-water nanofluid with a volume concentration of $0.5 \%$, heat transfer increased about $89 \%$.

Saeedinia et al. (2012), observed an increase of $45 \%$ in heat transfer by using a wire coil inserted tube and a nanofluid of $\mathrm{CuO} / \mathrm{base}$ oil with a volume concentration of $0.3 \%$ in the circular tube.

Chun et al. (2008) investigated the heat transfer of several $\mathrm{Al}_{2} \mathrm{O}_{3}$ nanoparticles in base fluid into a double pipe heat exchanger system in the laminar flow regime. In all of them, the heat transfer coefficient of nanofluid increased compared to the base fluids. Also, in all types of nanofluids, the overall heat transfer coefficient increased as Reynolds number of nanofluid increased. In another study by Duangthongsuk and Wongwises (2009), heat transfer enhancement of $\mathrm{TiO}_{2}-$ water nanofluid was investigated in a double-tube counter flow heat exchanger and under conditions of volume concentration of $0.2 \%$ and turbulent flow regime. They observed an increase of $6 \%$ to $11 \%$ for nanofluid compared with base fluid. It was also observed that with increasing the mass flow rate of hot water and nanofluid, the heat transfer coefficient increased.

Heat transfer performance of $\mathrm{TiO}_{2}-\mathrm{SiO}_{2}$ nanofluids in a tube with wire coil inserts was conducted by Abdul Hamid et al. (2019). They found that The thermal performance factor (TPF), $\eta$ for the nanofluids with wire coil inserts at all volume concentrations was observed greater than 1.0. The thermohydraulic performance of nanofluids in flat tubes automobile radiators was discussed by Arora and Gupta (2020). The effect of nanoparticle concentration, nanofluid flow rate (or Reynolds number), nanofluid temperature and tube geometry on heat and flow characteristics was critically analysed.

Leong et al. (2010) shows that in an automotive car radiator with copper nanoparticles in an ethylene glycol as the basefluid, by increasing the Reynolds number for inlet air and nanoparticle concentrations, the overall heat transfer coefficient of nanofluid increased, and at the Reynolds number of 6000 $(\mathrm{Re}=6000)$ and the volumetric concentration of $2 \%$, an increase of $18 \%$ in the overall heat transfer coefficient of the nanofluid was observed as compared to the base fluid. Peyghambarzadeh et al. (2011) tested the thermal performance of car radiator by using a $\mathrm{Al}_{2} \mathrm{O}_{3}$ - water as a coolant fluid and showed that an increase in the fluid flow rate would increase heat transfer; as well, the use of lowconcentration nanofluid can increase efficiency by $45 \%$. Leong et al. (2012) investigated the overall heat transfer coefficient of copper nanofluid in a water based fluid and ethylene glycol in a shell and tube heat exchanger under different amounts of flue gas flow rate and nanofluid flow rate as a coolant and different concentrations of nanofluid. In a laminar flow regime $\left(\operatorname{Re}_{\mathrm{cr}}=2000\right)$, they observed that in a mass flow rate of $26.3 \mathrm{~kg} / \mathrm{s}$ for flue gas and 111.6 $\mathrm{kg} / \mathrm{s}$ coolant fluid at $1 \%$ volume concentration of copper nanofluid in the ethylene glycol base fluid, $9.5 \%$ increase was observed in the overall heat transfer coefficient of the nanofluid in comparison with the ethylene glycol base fluid.

Ahmad et al. (2020) carried out a review on the thermal performance of nanofluid inside circular tube with twisted tape inserts. They summarized 109 of journals from recent research on heat transfer enhancement of nanofluid flowing inside the tube with inserts as well as discussing the significant parameters that affected the system's efficiency such as nanoparticles' volume fraction, Reynolds number and types and configurations of inserts.

As seen in these and/or similar studies, heat transfer mechanisms in an automotive cooling system could be very complicated and this geometry could be appeared in many industrial installations. The present research investigates the use of tube insert 
and also the replacement of nanofluid instead of conventional fluids such as water or ethylene glycol in the radiator. The simultaneous impact of these two was examined by simulating the cooling system of the car.

\section{EXPERIMENTAL DETAILS}

\subsection{Nanofluid}

The aluminum oxide $\left(\mathrm{Al}_{2} \mathrm{O}_{3}\right)$ and distilled water are used as the nanoparticles and base fluid, respectively. Aluminum oxide nanoparticles with a size of $40 \mathrm{~nm}$ were used.

\subsection{Nanofluid Stability}

According to the conducted studies in the field of nanofluid, three methods have been proposed for stabilizing the nanoparticle in the base fluid and preventing its sedimentation: 1) using ultrasonic vibration; 2) controlling the $\mathrm{pH}$ of the fluid; 3 ) use of surface active agents.

The last two methods help to improve the stability of nanofluids by modifying the surface of nanoparticles, but in the first method, ultrasound vibrations cause weak surface bonds between nanoparticles and thus break the agglomerates and increase the stability of the nanofluid.

The amount of nanoparticles used in the base fluid is not too high to affect the stability of the nanofluid. The prepared nanofluid in the present study remained stable for several days without any observable sedimentation. However, in this experiment, it is stabilized by the ultrasonic vibration before each test to prevent its deposition during rotation in the device.

\subsection{Ultrasonic Vibration Device}

Ultrasonic vibration device is used to stabilize soluble nanofluid about 1.5 liters by inserting the titanium probe of the device into solution for 45 minutes. In the Fig. (1) you can see it.

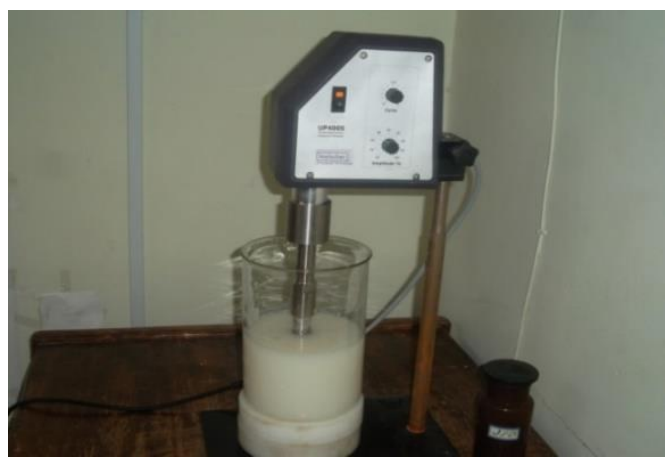

Fig. 1. Ultrasonic vibration device to stabilize $\mathrm{Al}_{2} \mathrm{O}_{3}$-Water nanofluid.

\subsection{Tube inserts}

To make turbulent the flow and change in the heat transfer coefficient, we use a wire with a special profile inside the radiator tube, which has a narrow channel mode, so that there is a slight drop in pressure and a good fit within the channel. For this purpose, a steel wire in the form of a sinusoidal wave with a diameter of $0.25 \mathrm{~mm}$ is used (up and down). The upper and lower amplitude is $7 \mathrm{~mm}$ and the distance between the two peaks is $9 \mathrm{~mm}$, Figs. 2 and 3 .

\subsection{Radiator}

For the heat exchange, a cross-flow aluminum plate fin type radiator with a length of $0.629 \mathrm{~m}$ and a width of $0.38 \mathrm{~m}$ was used. This exchanger includes 40 horizontal pipes, and each tube has a central separator plate. The radiator has a total of 80 tubes. The actual image is depicted in Fig. 4. The gap between the tubes is filled with thin aluminum blades that are perpendicular to the tubes. The cross section of the radiator tube is non-circular and has size of $0.00156 \mathrm{~m} \times 0.012 \mathrm{~m}$.

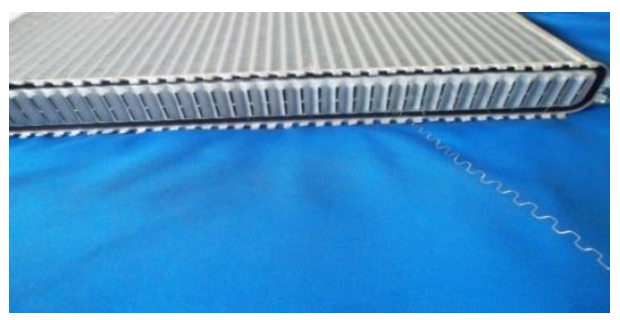

Fig. 2. Tube inserts.

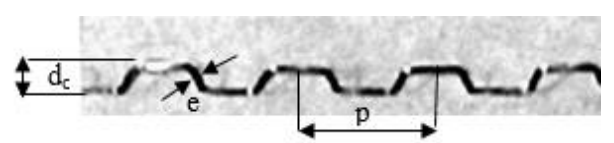

Fig. 3. Schematic figure of tube insert.

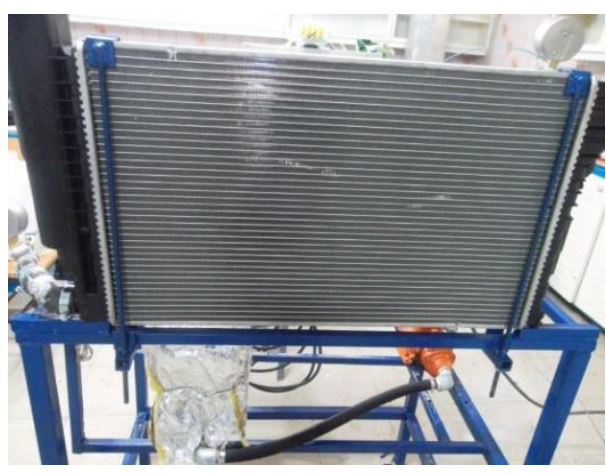

Fig. 4. Radiator.

\subsection{Experimental Apparatus}

Figure 5 shows the setup image. This experimental setup includes a reservoir tank $(0.35 \times 0.25 \times 0.15 \mathrm{~m})$, two electrical heaters $(6000 \mathrm{~W})$, a centrifugal pump $(0.8 \mathrm{~kW})$, flow meter $(0-25 \mathrm{lit} / \mathrm{min})$, tubes, valves, two fans (1400 rev/min), a DC power supply, manometer tube with mercury, automobile radiator (heat exchanger), 2 thermocouples (type $\mathrm{K}$ ) are used to measure the fluid temperature in the input and output of radiator. Other thermocouples are used for measuring the temperature on the radiator body wall. 
By connecting all the thermocouple to the data logger, temperature measured and recorded.

After calibration of the test apparatus, the relevant tests were first performed by distilled water as a scale in the calculations as follows: First, after dispensing 7 liters of distilled water into the storage tank and turning on the heaters and adjusting the temperature by the controller on the desired set point (the water inlet temperature to the radiator was adjusted to 44 ${ }^{\circ} \mathrm{C}$ ), the appropriate time was given for the heating of the water, and after it reached the desired temperature, the pump button is pressed.

To prevent evaporation, the door was placed on a storage.

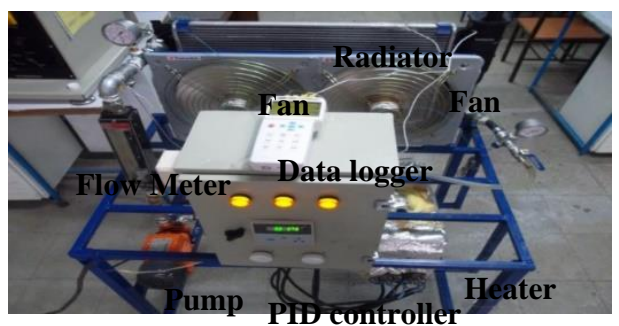

Fig. 5. Photograph of experimental setup.

tank. Then the flow rate of the water fluid is regulated by valves on the flow lines at a flow rate of 8 to $13.5 \mathrm{lit} / \mathrm{min}$, and then the fan button is turned on to cool the hot fluid by the air flow. All experimental data are recorded after 40 minutes to obtain reliable conditions in the experimental system. For $\mathrm{Al}_{2} \mathrm{O}_{3}$ water nanofluid, experiments are conducted in the same condition under three concentrations of $0.1,0.2$ and $0.4 \%$ weight fraction. Calibration of thermocouples carried out by using a constant temperature water bath and their accuracy estimated to be $0.2{ }^{\circ} \mathrm{C}$.

After ensuring the calibration of temperature, thermocouple, flowmeter and experimental device for water and $\mathrm{Al}_{2} \mathrm{O}_{3}$-water nanofluid, calculations are performed as follows. To perform calculations and obtain heat transfer coefficient, the following method has been used. We first use the following equations to obtain the equation related to heat transfer coefficient and the Nusselt number associated with each working fluid (water and nanofluid).

By Newton's law of cooling:

$\dot{\mathrm{Q}}=\mathrm{hA} \Delta \mathrm{T}=\mathrm{hA}\left(\mathrm{T}_{\mathrm{b}}-\mathrm{T}_{\mathrm{w}}\right)$

$\mathrm{T}_{\mathrm{b}}=\frac{\mathrm{T}_{\text {in }}+\mathrm{T}_{\text {out }}}{2}$

where $\mathrm{h}$ is the overall heat transfer coefficient, $\mathrm{A}$ is peripheral area of radiator tubes, $\mathrm{T}_{\mathrm{w}}$ is tube wall temperature which is the mean value by 4 surface thermocouples, and $T_{b}$ is bulk temperature which is assumed to be the average values of inlet and outlet temperature of the fluid moving through the radiator:

and
$\dot{\mathrm{Q}}=\dot{\mathrm{m}} \mathrm{C}_{\mathrm{p}} \Delta \mathrm{T}=\dot{\mathrm{m}} \mathrm{C}_{\mathrm{p}}\left(\mathrm{T}_{\text {in }}-\mathrm{T}_{\text {out }}\right)$

Where, $\mathrm{m}$ is mass flow rate which is the product of density and volume flow rate of fluid, and $C_{p}$ is the specific heat capacity of the fluid at a bulk temperature $T_{b}$.

By equating both of the above equations, we can obtain the experimental value of $h_{\text {exp }}$.

$\mathrm{h}_{\exp }=\frac{\dot{m} \mathrm{C}_{\mathrm{p}}\left(\mathrm{T}_{\text {in }}-\mathrm{T}_{\text {out }}\right)}{\mathrm{A}\left(\mathrm{T}_{\mathrm{b}}-\mathrm{T}_{\mathrm{w}}\right)}$

For Nusselt's equation:

$\mathrm{Nu}=\frac{\mathrm{h}_{\text {exp }} \mathrm{D}_{\mathrm{h}}}{\mathrm{k}}$

Where $\mathrm{Nu}$ is average Nusselt number for the whole radiator, $\mathrm{k}$ is fluid thermal conductivity and $\mathrm{D}_{\mathrm{h}}$ is

hydraulic diameter of the tube.

According to dimensions of the radiator tube $(\mathrm{d}=1.56$ $\mathrm{mm}, \mathrm{D}=12 \mathrm{~mm}$ ) in Fig. 6., hydraulic diameter of the tube can be obtained as:

$D_{h}=\frac{4 \times\left[\frac{\pi d^{2}}{4}+d \times(D-d)\right]}{\pi \times d+2 \times(D-d)}$

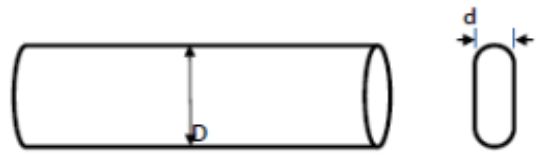

Fig. 6. Radiator tube configuration.

Therefore, the hydraulic diameter of the tube is calculated as $D_{h}=2.82 \mathrm{~mm}$.

The hydraulic diameter of the tube with tube insert can be calculated as follows (Fig. 3):

$d_{h}=\frac{D_{h}^{2}-\pi e^{2} d_{c} / p}{D_{h}+\pi e d_{c} / p}$

where yields $d_{h}=2.27 \mathrm{~mm}$.

The following equations are also defined.

$\operatorname{Re}=\frac{4 \dot{m}}{\pi \mu D_{h}}$

$\mathrm{U}=\frac{\mathrm{Q}_{1}}{\mathrm{~A}_{\mathrm{t}}}$

$\mathrm{Q}_{1}=\frac{\mathrm{Q}_{\mathrm{t}}}{80}$

The Reynolds number with the insert tube can be calculated by replacing $d_{h}$ instead of $D_{h}$.

where, $\mathrm{Q}_{\mathrm{t}}$ is the Volumetric flow rate in all tubes and $\mathrm{Q}_{1}$ is the volumetric flow rate of fluid within a radiator tube. 
A. Karimdoost Yasuri and E. Soleimani/ JAFM, Vol. 14, No. 5, pp. 1559-1566, 2021.

As described by Sharma (2018), it is supposed flows of fluid are distributed uniformly in all the tubes.

In the present work, we also use the Darcy equation to obtain a pressure drop. The friction factor in term of pressure drop $(\Delta \mathrm{p})$ can be expressed as:

$f=\frac{2 \Delta p D_{h}}{\rho U^{2} L}$

where, $\mathrm{D}_{\mathrm{h}}$ is the hydraulic diameter of a tube, and $\mathrm{L}$ is the length of a tube, the $\rho$ is density of the fluid passing through the tube, and $\mathrm{U}$ is the fluid velocity in a tube. The thermal properties of $\mathrm{Al}_{2} \mathrm{O}_{3}$ nanoparticle and base fluid are shown in Table1.

\subsection{Error Analysis}

The accuracy is a measure of the degree of closeness of a measured or calculated value to its actual value.

Accuracy of parameters are provided in table 2 .

Table 1 Thermo physical properties of fluid (Saleh et al. 2011).

\begin{tabular}{|c|c|c|}
\hline Properties & Water & $\mathrm{Al}_{2} \mathrm{O}_{3}$ \\
\hline $\begin{array}{c}\text { Thermal conductivity } \\
(\mathrm{W} / \mathrm{m} \mathrm{k})\end{array}$ & 0.6 & 46 \\
\hline Specific heat $(\mathrm{J} / \mathrm{kg}-\mathrm{K})$ & 4183 & 765 \\
\hline Viscosity $\left(\mathrm{N}-\mathrm{s} / \mathrm{m}^{2}\right)$ & 0.00089 & - \\
\hline Density $\left(\mathrm{Kg} / \mathrm{m}^{3}\right)$ & 997.1 & 3600 \\
\hline
\end{tabular}

Table 2 Accuracy of parameters.

\begin{tabular}{|c|c|c|}
\hline Parameters & Value & Accuracy \\
\hline $\mathrm{D}_{\mathrm{h}}$ & $2.82 \mathrm{~mm}$ & $0.0007 \mathrm{~mm}$ \\
\hline $\mathrm{L}$ & $629 \mathrm{~mm}$ & $0.001 \mathrm{~mm}$ \\
\hline $\mathrm{P}$ & $50 \mathrm{mbar}$ & $0.1 \mathrm{mbar}$ \\
\hline $\mathrm{T}_{\mathrm{w}}$ & $30^{\circ} \mathrm{C}$ & $0.1^{\circ} \mathrm{C}$ \\
\hline $\mathrm{T}_{\text {in }}$ & $43^{\circ} \mathrm{C}$ & $0.1^{0} \mathrm{C}$ \\
\hline $\mathrm{T}_{\text {out }}$ & $36^{\circ} \mathrm{C}$ & $0.1^{\circ} \mathrm{C}$ \\
\hline$\dot{\mathrm{m}}$ & $10 \mathrm{~L} / \mathrm{min}$ & $0.33 \mathrm{~L} / \mathrm{min}$ \\
\hline
\end{tabular}

The uncertainties of experimental measurements are determined by the method introduced by Kline and McClintock (1953) and the following equation,

$\delta R=\left[\sum_{j=1}^{M}\left(\frac{\partial R}{\partial X_{j}} \delta X_{j}\right)^{2}\right]^{1 / 2}$

where $\mathrm{j}, \mathrm{M}, \delta \mathrm{R}$, and $\delta \mathrm{X}_{\mathrm{j}}$ are the specific parameter counter, number of the independent variables, uncertainties associated with the dependent, R, and independent, $\mathrm{X}_{\mathrm{j}}$, variables, respectively.

The uncertainties for determining the friction factor, pressure drop and average heat transfer coefficient in this study are given in table 3 .
Table 3 Uncertainties of parameters.

\begin{tabular}{|c|c|}
\hline Parameters & Uncertainty (\%) \\
\hline $\mathrm{f}$ & 8.5 \\
\hline$\Delta \mathrm{p}$ & 10 \\
\hline $\mathrm{h}$ & 12 \\
\hline
\end{tabular}

\subsection{Verification}

By looking at the results of distilled water at $40{ }^{\circ} \mathrm{C}$, Fig. 7 shows variation of the heat transfer coefficient in terms of the Reynolds number inside the radiator tubes.

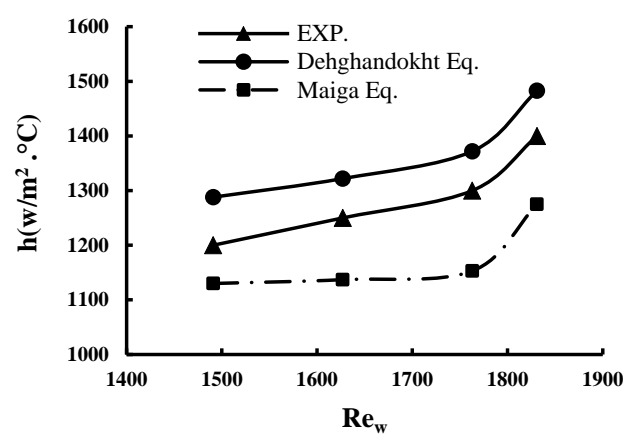

Fig. 7. Variation of heat transfer coefficient versus Reynolds number for distilled water compared with experimental correlations at $40^{\circ}$ C.

We compare the results of the experiment with the results of the Dehghandokht et al. (2011) correlation, and also the experimental equation of Maiga et al. (2005). As shown, reasonably good agreement can be seen between Dehghandokht equation and the measurements over the Reynolds number range used in this study.

\section{RESULT AND DISCUSSION}

Figure 8 shows the variation of the heat transfer coefficient in terms of Reynolds number for three concentrations of $0.1,0.2$ and $0.4 \%$ weight fraction of $\mathrm{Al}_{2} \mathrm{O}_{3}$-water nanofluid compared to water. For variations of Reynolds, the inlet nanofluid flow rate to the radiator is varied from 8 to $13.5 \mathrm{lit} / \mathrm{min}$, and average temperature is $40 \mathrm{C}^{\circ}$.

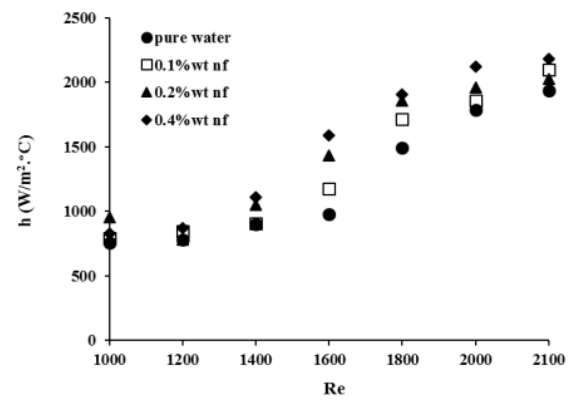

Fig. 8. Variations of heat transfer coefficient in terms of Reynolds number for three different concentrations of nanofluid $\left(\mathrm{Al}_{2} \mathrm{O}_{3}\right.$-water) compared with water. 
As shown in Fig. 8, as Reynolds number of the fluid in the tube increases, the amount of heat transfer coefficient increases. Also, the amount of heat transfer coefficient increases with an increase in the weight fraction of nanofluid and this increase for nanofluid with weight fraction of $0.1 \%$ is about $12 \%$. As the figure shows, Reynolds number variations relative to the weight fraction variations for the heat transfer coefficient acts as a dominant parameter.

Figure 9 shows the variation of the heat transfer coefficient in terms of Reynolds number for distilled water with tube insert and without it. As shown, the heat transfer coefficient increased as Reynolds number increased with the use of the tube insert. This increase is about $35 \%$ which is a significant.

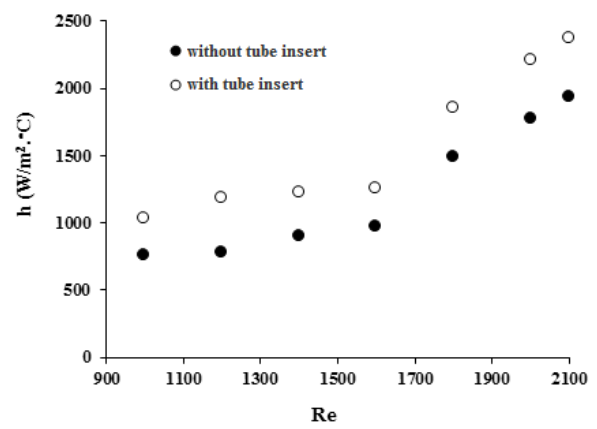

Fig. 9. Variations of heat transfer coefficient in terms of Reynolds number for distilled water with tube insert and without tube insert.

Figures 10 Shows the variations of the pressure drop across the radiator tubes in terms of flow rate in the presence of tube insert. By increasing the flow rate passing of the radiator, the amount of pressure drop due to the use of the tube insert increases.

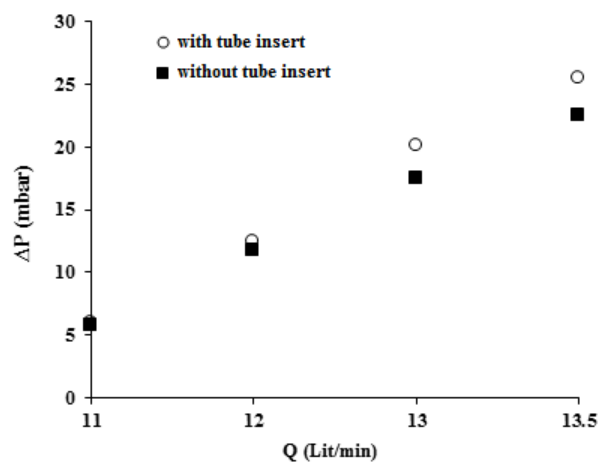

Fig. 10. Variations of the pressure drop within the radiator tubes in terms of flow rate in the presence of tube insert.

Figure 11 shows the comparison of the variations of the heat transfer coefficient in terms of Reynolds number for the three concentrations of $0.1,0.2$ and 0.4 nanofluid $\left(\mathrm{Al}_{2} \mathrm{O}_{3}\right.$-water $)$ with tube insert.

Figure 11 shows the performance of tube insert with $\mathrm{Al}_{2} \mathrm{O}_{3}$-water nanofluid. It can be seen that with increasing nanofluid concentration and simultaneous application of the intubation tube, the heat transfer coefficient increases compared to pure water $(0 \% \mathrm{wt}$ nf) in the absence of an inert tube. The value of heat transfer coefficient increased about 55\% using $\mathrm{Al}_{2} \mathrm{O}_{3}$-water nanofluid with tube insert.

However, the final performance should be measured by evaluating the pressure drop that is caused by the use of a nanofluid with the intubation tube. In the following, we examine and evaluate the performance of the insert tube with the relation of thermohydraulic

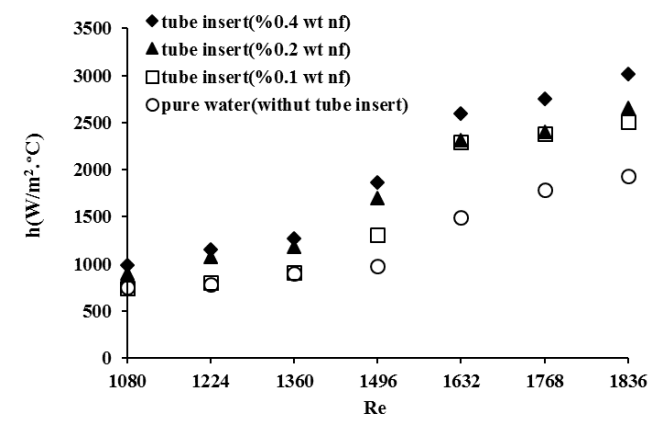

Fig. 11. Comparison of variations in the heat transfer coefficient in terms of Reynolds number for three concentrations of $0.1,0.2$ and $0.4 \%$

$\mathrm{Al}_{2} \mathrm{O}_{3}$-water nanofluid with tubes insert (water with tube insert).

performance. The effectiveness of a heat transfer improvement technique can be evaluated by the thermal performance factor $(\eta)$ which represents the ratio of the relative effect of change in heat transfer rate to change in friction factor. It is defined by following equation (Maradiya et al. 2018):

$\eta=\frac{\frac{N u_{t u b}}{N u}}{\left(\frac{f_{t u b}}{f}\right)^{1 / 3}}$

Where friction factor $=\frac{\Delta p}{\left(\rho U^{2} / 2\right)\left(L / D_{h}\right)}$. Figure

12 shows the thermal performance factor obtained with the use of nanoparticles with tube insert and various weight fractions of nanofluid $(0.1,0.2$ and $0.4 \%$ ) with Reynolds number.

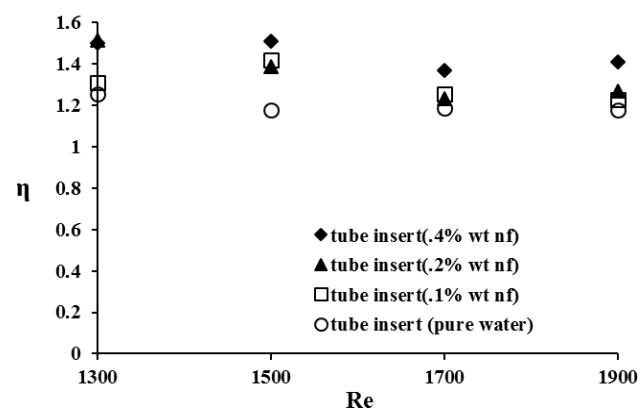

Fig. 12. Variation of thermal performance factor with Reynolds number for $0.1,0.2$ and $0.4 \%$ weight fraction.

As shown, the performance of the insert tube is greater than the unit, indicating that the use of inert tube inside the radiator is practically reasonable and 
affordable. Of course, it's less effective in the high Reynolds.

Also thermal performance increases as the weight fraction increases. This indicates that the use of nanofluid is feasible in terms of energy saving in laminar regime.

The use of nanofluid with higher concentration provides noticeably higher thermal performance for all of the Reynolds number considered. This is because of a superior efficiency of nanofluid disturbance and thus heat transfer caused by the nanofluid compared to the base fluid at the same pumping power.

The nanofluids with higher mass concentration have higher pressure drop due to their greater viscosity values, therefore, after a certain mass concentration, friction factor enhancement overcomes the Nusselt number increment and thermal performance factor decreases.

However, in the range of mass concentration considered in present study, the increase in thermal performance factor with increase in mass concentration is mainly due to the higher augmentation in Nusselt number than the increment of friction factor.

\section{Conclusions}

The most important outcomes of this study are summarized as follows:

1. By increasing Reynolds number of the $\mathrm{Al}_{2} \mathrm{O}_{3}$ water nanofluids, the heat transfer coefficient increased and on average by increasing Reynolds, from 1020 to 1830 , an increase of about $13 \%$ was obtained for the heat transfer coefficient of $\mathrm{Al}_{2} \mathrm{O}_{3}$-water.

2. Increasing the concentration of $\mathrm{Al}_{2} \mathrm{O}_{3}$-water nanofluid from $0.1 \%$ to $0.4 \%$ of weight fraction resulted in an increase in the $\mathrm{Al}_{2} \mathrm{O}_{3}$ water heat transfer coefficient compared to fluid base of the distilled water. That is, increasing the concentration in the high reynolds has a greater and better effect than similar conditions in the lower Reynolds.

3. Using tube insert alone not only was possible but also it had an acceptable thermal performance and the heat transfer coefficient increased by an average of $35 \%$.

4. Using the experiment data, it is concluded that the use of tube insert in an $\mathrm{Al}_{2} \mathrm{O}_{3}$-water nanofluid with a concentration of 0.4 weight fraction increased the heat transfer coefficient up to $55 \%$.

\section{REFERENCES}

Abdul Hamid, K., W. H. Azmi, R. Mamat and K. V. Sharma (2019). Heat transfer performance of $\mathrm{TiO}_{2}-\mathrm{SiO}_{2}$ nanofluids in a tube with wire coil inserts. Applied Thermal Engineering 152, 275-286.
Ahmad, S., S. Abdullah and K. Sopian (2020). A review on the thermal performance of nanofluid inside circular tube with twisted tape inserts. Advances in Mechanical Engineering 12(6), 1-26.

Arora, N. and M. Gupta (2020). An updated review on application of nanofluids in flat tubes radiators for improving cooling performance. Renewable and Sustainable Energy Reviews 134, 110242.

Chandrasekar, M., S. Suresh and A. Chandra Bose (2011). Experimental studies on heat transfer and friction factor characteristics of $\mathrm{Al}_{2} \mathrm{O}_{3} /$ water nanofluid in a circular pipe under transition flow with wire coil inserts. Heat Transfer Engineering 32(6), 485-496.

Choi, S. U. S. (1995). Enhancing thermal conductivity of fluids with nanoparticles, Developments and Applications of NonNewtonian Flows. FED 231/MD 66, 99-105.

Choi, C., H. S. Yoo and J. M. Oh (2008). Preparation and heat transfer properties of nanoparticle-intransformer oil dispersions as advanced energy-efficient coolants. Current Applied Physics 8,710-712.

Chun, B., H. Kang and S. Kim (2008). Effect of alumina nanoparticles in the fluid on heat transfer in double-pipe heat exchanger system, Korean Journal of Chemical Engineering 25(5), 966-971.

Duangthongsuk, W. and S. Wongwises (2009). Heat transfer enhancement and pressure drop characteristics of $\mathrm{TiO}_{2}$-water nanofluid in a double-tube counter flow heat exchanger. International Journal of Heat and Mass Transfer 52, 2059-2067.

Dehghandokht, M., M. G. Khan, A. Fartaj and S. Sanaye (2011). Flow and heat transfer characteristics of water and ethylene glycolewater in a multi-port serpentine mesochannel heat exchanger. International Journal of Thermal Sciences 50, 1615-1627.

Kline, S. J. and F. A. McClintock (1953). Describing uncertainties in single sample experiments. Mechanical Engineering 75, 385-387.

Leong, K. Y., R. Saidur, T. M. I. Mahlia and Y. H. Yau (2012). Modeling of shell and tube heat recovery exchanger operated with nanofluid based coolants. International Journal of Heat and Mass Transfer 55, 808-816.

Leong, K. Y., R. Saidur, S. N. Kazi and A. H. Mamun (2010). Performance investigation of an automotive car radiator operated with nanofluid-based coolants (nanofluid as a coolant in a radiator). Applied Thermal Engineering 30, 2685-2692.

Maiga, S. E., S. J. Palm, C.T. Nguyen, G. Roy and N. Galanis (2005). Heat transfer enhancement by using nanofluids in forced convection flows. Int. J. Heat and Fluid Flow 26, 530-546. 
A. Karimdoost Yasuri and E. Soleimani/ JAFM, Vol. 14, No. 5, pp. 1559-1566, 2021.

Maradiya, C., J. Vadher and R. Agarwal (2018). The heat transfer enhancement techniques and their Thermal Performance Factor. Beni-Suef University Journal of Basic and Applied Sciences 7(1), 1-2.

Peyghambarzadeh, S. M., S. H. Hashemabadi, S. M. Hoseini and M. Seifi Jamnani (2011). Experimental study of heat transfer enhancement using water/ethylene glycol based nanofluids as a new coolant for car radiators. International Communications in Heat and Mass Transfer 38(9), 1283-1288.

Saleh, H., R. Roslan and I. Hashim (2011). Natural convection heat transfer in a nanofluid-filled trapezoidal enclosure. International Journal of Heat and Mass Transfer 54, 194-201.

Sharma, S. (2018). Fabricating an experimental setup to investigate the performance of an automobile car radiator by using aluminum/water nanofluid. Journal of Thermal Analysis and Calorimetry 133, 13871406
Sharma, K. V., L. Syam Sundar and P. K. Sarma (2009). Estimation of heat transfer coefficient and friction factor in the transition flow with low volume concentration of $\mathrm{Al}_{2} \mathrm{O}_{3}$ nanofluid flowing in a circular tube and with twisted tape insert. International Communications in Heat and Mass Transfer 36, 503-507.

Saeedinia, M., M. A. A. Behabadi and M. Nasr (2012). Experimental study on heat transfer and pressure drop of nanofluid flow in a horizontal coiled wire inserted tube under constant heat flux. Experimental Thermal and Fluid Science 36, 158-168.

Sundar, S. L. and K. V. Sharma (2010). Turbulent heat transfer and friction factor of $\mathrm{Al}_{2} \mathrm{O}_{3}$ nanofluid in circular tube with twisted tape inserts. International Journal of Heat and Mass Transfer 53, 1409-1416. 